BRE 14230

\title{
Cocaine: evidence for supraspinal, dopamine-mediated, non-opiate analgesia
}

\author{
Yu Lin ${ }^{3}$, Thomas J. Morrow ${ }^{2,3}$, Judith A. Kiritsy-Roy ${ }^{3}$, \\ L. Cass Terry ${ }^{1,2,3}$ and Kenneth L. Casey ${ }^{1,2,3}$ \\ Departments of ${ }^{1}$ Neurology and ${ }^{2}$ Physiology, University of Michigan and ${ }^{3}$ Neurology Research Laboratories, \\ Veterans Administration Medical Center, Ann Arbor, MI 48105 (U.S.A.)
}

(Accepted 26 July 1988)

Key words: Pain; Rat; Behavior; Morphine; Cocaine; Dopamine

\begin{abstract}
Cocaine ( $25 \mathrm{mg} / \mathrm{kg}$ i.p.) produces analgesia in the rat within $5 \mathrm{~min}$ and for a duration of $90 \mathrm{~min}$ as determined by the formalin test or for $30 \mathrm{~min}$ as determined by the hot plate test. Cocaine analgesia is unaffected by doses of naloxone that are sufficient to attenuate morphine analgesia in both tests. Chlorpromazine ( $3 \mathrm{mg} / \mathrm{kg}$ i.p.), SCH 23390 (100 $\mu \mathrm{g} / \mathrm{kg}$ i.p.; a $\mathrm{D}_{1}$ dopamine receptor antagonist), and eticlopride ( $75 \mu \mathrm{g} / \mathrm{kg}$ i.p.; $\mathrm{a} \mathrm{D}_{2}$ dopamine receptor antagonist) each attenuate cocaine analgesia in both tests at doses that alone do not affect performance in either test. Measurements of blood pressure and heart rate indicate that cocaine analgesia is not due to the activation of baroreceptor reflex afferents. We conclude that cocaine is a supraspinally acting, dopamine-mediated, non-opiate analgesic in the rat.
\end{abstract}

\section{INTRODUCTION}

The central nervous system action of systemically administered analgesic compounds is thought to be mediated primarily, if not exclusively, by neural mechanisms also activated by opiate receptors ${ }^{12,18}$. Neurons containing norepinephrine and serotonin form essential connecting links in the opiate-activated analgesia mechanism ${ }^{12,35}$. Because cocaine blocks the deactivating re-uptake of biogenic amines in the central nervous system ${ }^{30,32}$, we considered that cocaine might have potent systemic analgesic properties. Furthermore, cocaine's action could bypass opiate receptor mechanisms because it is not an opiate narcotic. it has long been known that sympathomimetic agents can produce analgesia ${ }^{5,25}$, but we found only 3 short anecdotal reports on the analgesic effect of systemically administered cocaine in $\operatorname{dogs}^{20,27}$ and a human ${ }^{16}$. Yang et al. ${ }^{36}$ showed that cocaine applied intranasally attenuated ischemic pain (tourniquet test) in humans, but this effect could not be related securely to a systemic action, and opiate mediation was not tested. We therefore undertook a systematic investigation of cocaine as a systemic analgesic.

\section{MATERIALS AND METHODS}

All experiments were conducted using male Sprague-Dawley rats (250-400 g) maintained in facilities fully accredited by the American Association for the Accreditation of Laboratory Animal Care.

Analgesia was evaluated by both the formalin and hot plate tests. In the formalin test ${ }^{9}, 0.05 \mathrm{ml}$ of sterile $5 \%$ formalin was injected subcutaneously into the dorsum of one forepaw. Every 5-10 min, pain behavior was graded throughout a $3 \mathrm{~min}$ observation period according to the proportion of time (seconds) the paw was held up and licked (grade 3), held fully elevated (grade 2), partially weight bearing (grade 1 ), or fully weight bearing (grade 0 ). The sum of the products of each grade and the time spent in that grade was divided by $180 \mathrm{~s}$ to yieid a pain intensity score. In the hot plate test ${ }^{22}$, each rat was placed

Correspondence: K.L. Casey, Neurology Service (127), Veterans Administration Medical Center, Ann Arbor, MI 48105, U.S.A. 
within a clear plexiglass cylinder on a copper surface maintained at $52.5^{\circ} \mathrm{C}$ by circulating water. The latency to hind paw lick or escape was determined and the test was terminated after $45 \mathrm{~s}$. The baseline latency $(B)$ was the average of 3 latency measurements made at $5 \mathrm{~min}$ intervals before administering drugs. Latencies $(L)$ measured at intervals after drug administration were used to calculate $\%$ analgesia $(=[(L-B) /(45-B)] \times 100)$. The significance of differences in pain scores (formalin test), \% analgesia (hot plate test), or cardiovascular measurements was evaluated by computing the $95 \%$ confidence intervals about each mean. Compared means were considered significantly different when each fell outside the confidence limit of the other.

To determine if drug-induced motor deficits interfered with the hot plate test, we used the abnormal posture test of $\mathrm{Fog}^{13}$. One hindpaw of the rat was placed on a cork with a height of $3.5 \mathrm{~cm}$, and the latency to movement off the cork was measured up to a maximum of $45 \mathrm{~s}$.

Blood pressure and heart rate responses to cocaine or saline were determined in 13 rats. Five days before the experiment, rats were surgically implanted with a chronic polyethylene cannuia (PE50) in the left internal carotid artery. The cannula was exteriorized at the scalp and passed through a stainless-steel spring, which was anchored to the skull with dental acrylic and screws. Blood pressure was recorded directly in conscious, freely-moving rats using a Grass Model 7

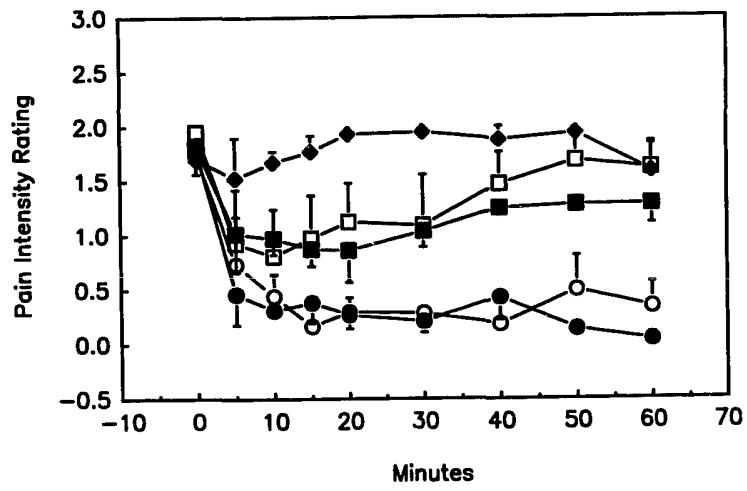

Fig. 1. Effect of different intraperitoneal doses of cocaine on averaged ( \pm S.E.M.) pain intensity ratings in the formalin test. Formalin $(5 \%, 0.05 \mathrm{ml})$ was injected subcutaneously into one forepaw $30 \mathrm{~min}$ before 0 time on the abscissa. Cocaine was administered at time $\mathbf{0}$. Four rats were in each dosage group. Filled diamonds, $5 \mathrm{mg} / \mathrm{kg}$; open squares, $10 \mathrm{mg} / \mathrm{kg}$; filled squares, $15 \mathrm{mg} / \mathrm{kg}$; open circles, $20 \mathrm{mg} / \mathrm{kg}$; filled circles, 25 $\mathrm{mg} / \mathrm{kg}$.
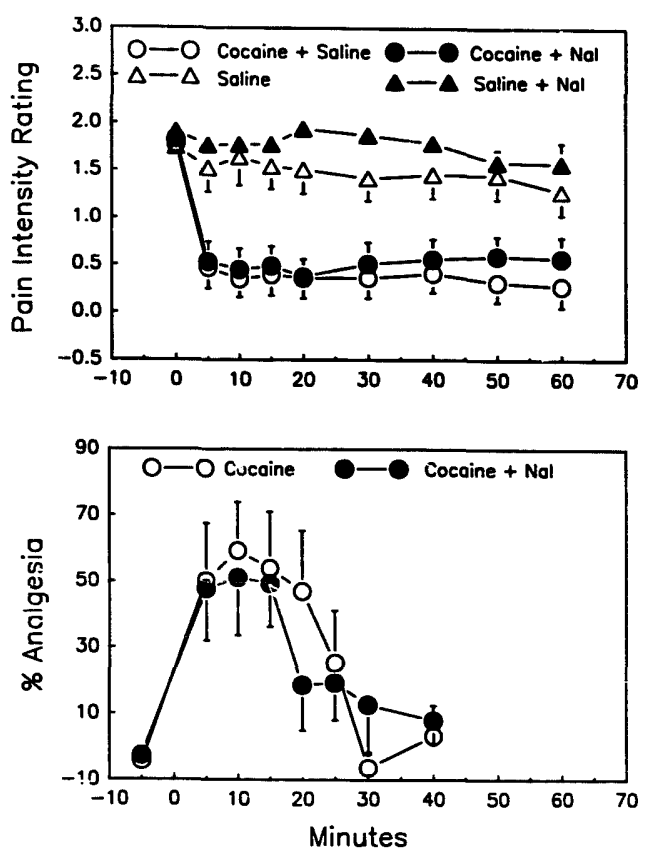

Fig. 2. Lack of effect of naloxone ( $1 \mathrm{mg} / \mathrm{kg}$, i.p.) on cocaine $(25$ $\mathrm{mg} / \mathrm{kg}$, i.p.) analgesia. Top: formalin test in blinded format. At time $\mathbf{0 , 3 0}$ min after subcutaneous formalin injection, each rat received 2 separate injections within $1 \mathrm{~min}$. Average ( \pm S.E.M.) pain ratings shown for each group of rats receiving cocaine and saline $(n=9)$, cocaine and naloxone $(n=9)$, saline and naloxone $(n=10)$, and saline oniy $(n=8)$. Bottom: hot plate test. Average ( \pm S.E.M.) $\%$ analgesia (see Methods) shown for rats receiving cocaine $(n=8)$ or cocaine followed immediately by naloxone $(n=8)$ at time 0 .

polygraph and Statham P23 pressure transducers. Heart rate was counted from the pressure tracing. Cardiovascular parameters were monitored for 15 min before administration of cocaine ( $25 \mathrm{mg} / \mathrm{kg}$ i.p.) or saline $(1 \mathrm{ml} / \mathrm{kg}$ i.p.). Blood pressure was monitored continuously for $\mathbf{4 0} \mathrm{min}$ after treatment and heart rate was sampled over $20 \mathrm{~s}$ epochs at $1,5,15,25$ and $40 \mathrm{~min}$ after treatment.

All drugs were given by intraperitoneal injection. Cocaine was prepared in sterile $25 \mathrm{mg} / \mathrm{ml}$ multiple injection vials by the pharmacy at the Veterans Administration Medical Center. The concentration of cocaine was independently verified on two occasions by the Toxicology Laboratory at the University of Michigan. The prototype dopamine $D_{1}$ and $D_{2}$ receptor antagonists, SCH 23390 and eticlopride, respectively, were both obtained from Research Biochemicals (Natick, MA). Fresh solutions in bacteriostatic saline were prepared daily; SCH 23390 was first dissolved in a minimum volume of $10 \%$ acetic acid. 


\section{RESULTS}

Cocaine injected intraperitoneally produced a dose-dependent analgesia as determined in 20 rats by the formalin test (Fig. 1). At maximally effective doses (20-25 mg/kg, i.p.), analgesia was clearly detectable within $5 \mathrm{~min}$ and sustained for $1-1.5 \mathrm{~h}$ in most rats. During the analgesic period, rats showed a slight to moderate increase in exploratory behavior that did not interfere with execution of the test. Otherwise, behavior appeared normal and without evidence for weakness or ataxia. Cocaine $(25 \mathrm{mg} / \mathrm{kg}$, i.p.) also produced analgesia as determined by the hot plate test (Fig. 2). The response peaked at 5-10 min but, in contrast with the formalin test, the duration of analgesia was limited to approximately 30 min. In preliminary experiments using the tail flick test $^{6}$, we found that the higher doses of cocaine produced, in the awake, restrained rat, enough increased spontaneous movement to make measurements unreliable (data not shown).
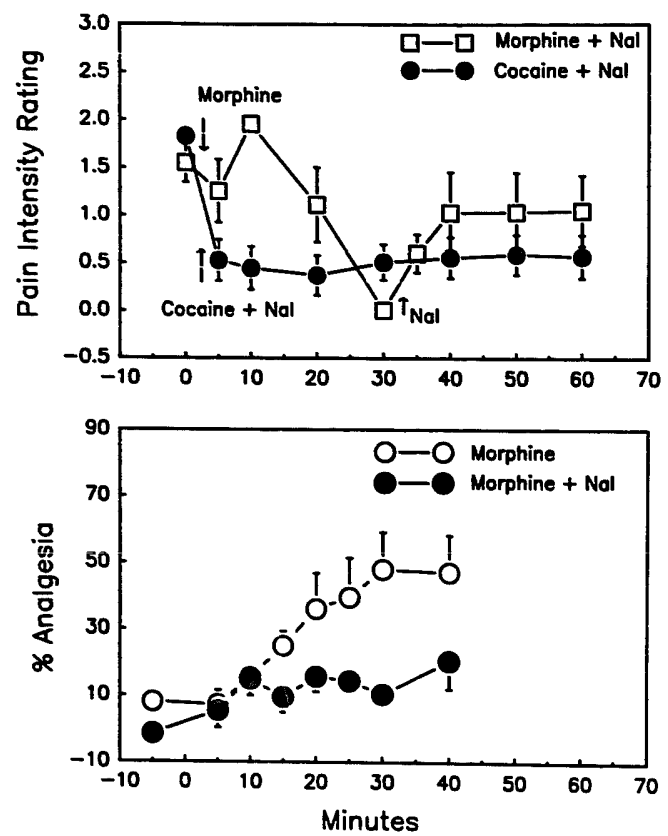

Fig. 3. Effect of naloxone $(1 \mathrm{mg} / \mathrm{kg}$, i.p.) on morphine analgesia. Top: formalin test. Arrows indicate time of drug injection. Morphine ( $6 \mathrm{mg} / \mathrm{kg}$, i.p.; $n=5$ ) produces analgesia more slowly than cocaine $(25 \mathrm{mg} / \mathrm{kg}$, i.p.; $n=9)$ and, unlike cocaine, morphine analgesia is attenuated by naloxone. Bottom: hot plate test. Morphine $(12 \mathrm{mg} / \mathrm{kg}$, i.p.) analgesia $(n=7)$ fails to develop when naloxone $(1 \mathrm{mg} / \mathrm{kg}$, i.p.) is injected immediately before morohine at time $0(n=7)$.

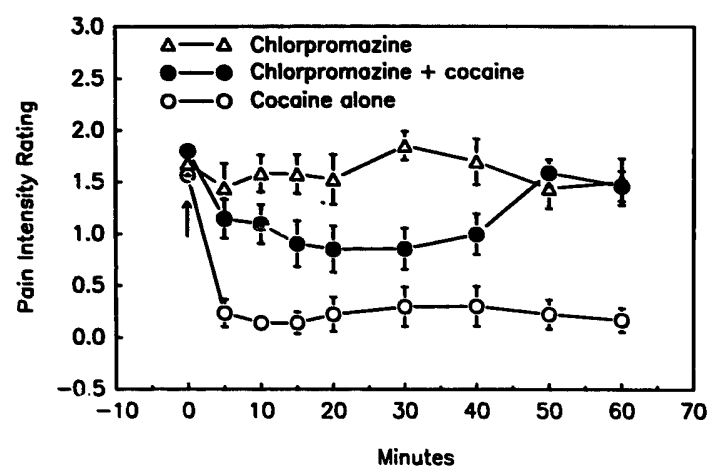

Fig. 4. Chlorpromazine (CPZ; $3 \mathrm{mg} / \mathrm{kg}$, i.p.) attenuation of cocaine $(25 \mathrm{mg} / \mathrm{kg}$, i.p.) analgesia in the formalin test. CPZ and cocaine were separately administered within one minute after time 0. CPZ alone had no effect $(n=6) . n=15$ (cocaine alone) and 12 (CPZ and cocaine).

Naloxone had no effect on cocaine analgesia in sither the formalin or hot plate test (Fig. 2). In the formalin test, a blind format was used to test 36 rats divided into 4 groups; neither the person preparing the solutions nor the person performing the test knew which treatment any rat received. The dose of naloxone we used $(1 \mathrm{mg} / \mathrm{kg})$ was sufficient to attenuate morphine analgesia in both formalin and hot plate tests (Fig. 3).

Because of the evidence that other behavioral effects of cocaine are mediated in part by dopaminergic mechanisms ${ }^{33}$, we determined the effect of the dopamine receptor antagonist, chlorpromazine (CPZ) on cocaine analgesia. When administered at a dose of 3 $\mathrm{mg} / \mathrm{kg}$, i.p., CPZ alone had no effect on the formalin test of pain behavior but significantly reduced the intensity and duration of cocaine analgesia (Fig. 4).

To examine further the dopamine receptor mechanisms that might mediate cocaine analgesia, rats were pretreated with either SCH 23390 , a $D_{1}$ selective antagonist ${ }^{17}$ or eticlopride, a $D_{2}$ selective antagonist $^{8}$. In the formalin test (Fig. 5), both SCH 23390 $(100 \mu \mathrm{g} / \mathrm{kg}$, i.p.) and eticlopride (75 $\mu \mathrm{g} / \mathrm{kg}$, i.p.) blocked the analgesic effect of cocaine at doses that alone had no effect on the test. In the hot plate test (Fig. 6), eticlopride and SCH 23390 both significantly attenuated cocaine analgesia; neither of these dopamine receptor antagonists interfered with the hot plate test when administered alone at the above doses. In addition, these compounds produced no evidence of motor impairment as assessed by the abnormal posture test (see Methods) at doses and times 


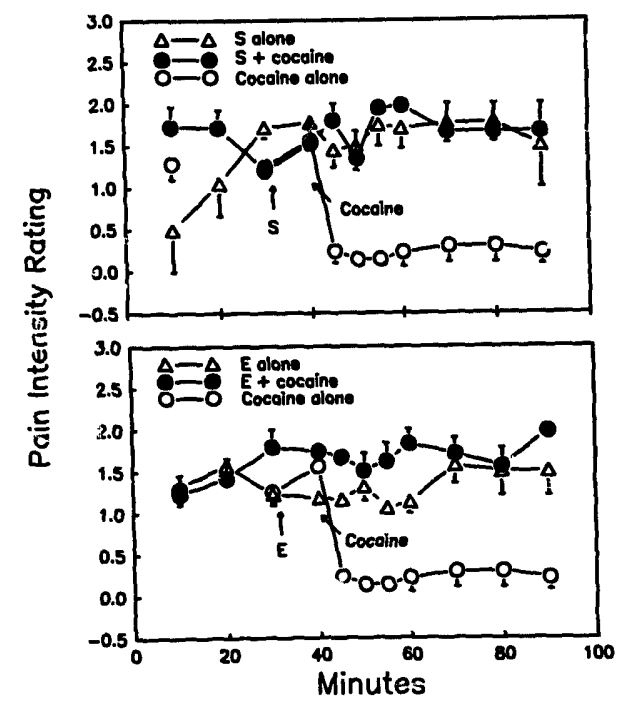

Fig. 5. $\mathrm{D}_{1}$ receptor antagonist, $\mathrm{SCH} 23390(\mathrm{SCH}, 100 \mu \mathrm{g} / \mathrm{kg}$, i.p., top panel), and $D_{2}$ receptor antagonist, eticlopride $(E$, $75.5 \mu \mathrm{g} / \mathrm{kg}$, i.p., bottom panel), given $10 \mathrm{~min}$ before cocaine ( 25 $\mathrm{mg} / \mathrm{kg}$, i.p.), each prevent cocaine analgesia without affecting the formalin test when given alone. Arrows indicate time of drug injection. $n=4$ (SCH alone), 3 ( $\mathrm{SCH}+$ cocaine), 4 ( $\mathrm{E}$ alone), 3 ( $E+$ cocaine), and 6 (cocaine alone).

corresponding to the block of cocaine analgesia.

There is evidence that acutely increasing arterial blood pressure in rats can produce an analgesia that is correlated with the reflex bradycardia mediated by baroreceptor activation $^{10,25}$. Analgesic doses of cocaine produced a significant increase in systolic blood pressure within the first minute after the injection, but subsequent measurements for $\mathbf{4 0}$ min thereafter

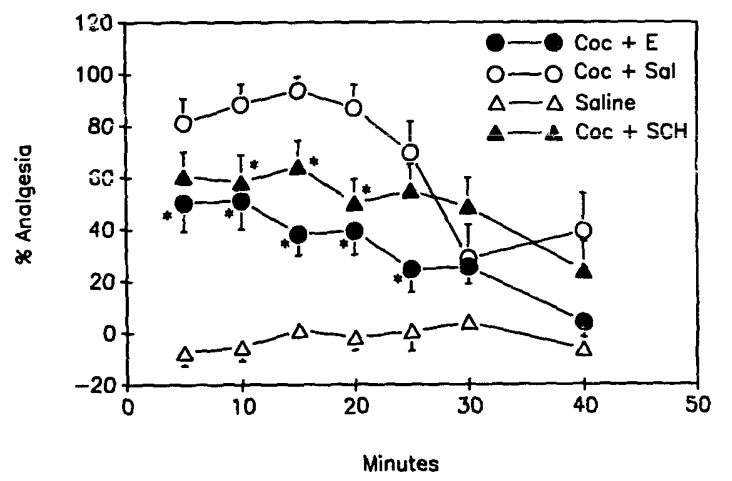

Fig. 6. Hot plate test. Eticlopride (E; $75.5 \mu \mathrm{g} / \mathrm{kg}$, i.p.) and $\mathrm{SCH}$ 23390 (SCH; $100 \mu \mathrm{g} / \mathrm{kg}$, i.p.) each block cocaine $(25 \mathrm{mg} / \mathrm{kg}$, i.p.) analgesia when given $10 \mathrm{~min}$ before cocaine injection at time $0 . n=14(\mathrm{SCH}+$ cocaine $), 15(\mathrm{E}+$ cocaine $), 12$ (cocaine + saline), and 6 (saline). Asterisks indicate points of significant attenuation of cocaine analgesia. showed no difference compared to animals injected with saline (Fig. 7). The transient hypertension was accompanied by a significant bradycardia for only 5 $\min$.

\section{DISCUSSION}

The analgesic effect of systemically administered cocaine has been demonstrated in this study by two different measures of supraspinally organized nocifensive behaviors. The formalin test elicits a prolonged behavioral response to a chemically-induced inflammation, whereas the hot plate test elicits a short duration, abrupt response to a thermal stimulus. By both measures, analgesia elicited by 20-25
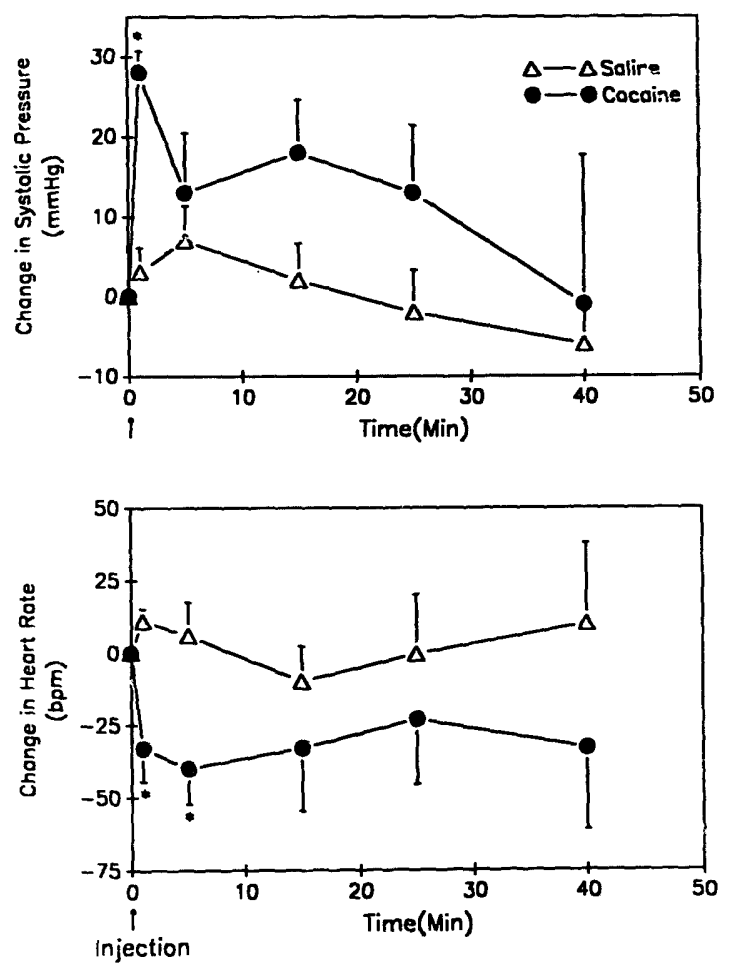

Fig. 7. Cardiovascular effects of cocaine $(25 \mathrm{mg} / \mathrm{kg}$, i.p. $)$. Cocaine $(n=7)$ or saline $(n=6)$ was injected at time 0 . Top: cocaine (circles) significantly increased systolic blood pressure at $1 \mathrm{~min}$ afier injection compared to saline-treated controls (triangles). Systolic pressure before injection: cocaine group, $125 \pm$ $9 \mathrm{~mm} \mathrm{Hg}$; saline group, $132 \pm 7 \mathrm{~mm} \mathrm{Hg}$. Bottom: cocaine decreased heart rate at 1-5 min after injection compared to controls. Heart rate before injection: cocaine group, $369 \pm 35$ bpm; saline group, $423 \pm 32 \mathrm{bpm}$. There were no significant differences in pretreatment blood pressure or heart rate between treatment groups. Asterisks indicate means that are significantly different from zero change and from the means of saline controls. 
$\mathrm{mg} / \mathrm{kg}$ of cocaine appears comparable in intensity to the analgesia produced by $6-12 \mathrm{mg} / \mathrm{kg}$ of morphine; at these doses, the analgesic effect of cocaine is more rapid in onset and, in the hot plate test, shorter in duration (Fig. 3). However, a definitive comparison of the potency and efficacy of these two analgesics will require additional studies using several dosage levels of each drug.

Our results in.ticate that the analgesia produced by parenterally administered cocaine is due to its action on nociceptive mechanisms within the central nervous system. We saw no evidence for motor deficits that would be expected if peripheral motor or kinesthetic mechanisms were affected by local anesthetic block. The attenuation and reversal of cocaine analgesia by dopamine antagonists also argues for a central effect on monoaminergic synaptic transmission rather than local anesthetic block of conduction in peripheral fibers. Furthermore, other experiments in our laboratory have shown that analgesic parenteral doses of cocaine do not affect the conduction of impulses into the cutaneous terminals of unmyelinated nociceptive afferents ${ }^{23}$. The same dose of cocaine dramatically alters, over a time course paralleling the behavioral effects, the spontaneous and nociceptively evoked activity of bulboreticular neurons that project rostrally or to the spinal cord ${ }^{1}$. It is possible, however, that the more prolonged analgesic effect of cocaine in the formalin, as compared to the hot plate, test is in part due to a peripheral anti-inflammatory effect of adrenal steroids in view of the recent finding that cocaine causes the release of adrenccorticotropic hormone in vitro ${ }^{28}$.

Systemic cocaine analgesia appears not to be caused by the activation of baroreceptors. In our experiments, cocaine produced a transient hypertension but did not induce the prolonged bradycardia associated with baroreceptor-activated analgesia ${ }^{10,25}$. Similar results have been reported by others ${ }^{24}$. A dissociation of cardiovascular responses and analgesia has recently been demonstrated during vaginocervical probing and phenylephrine injection in the rat ${ }^{3}$. Furthermore, naloxone reverses the analgesia of chronically hypertensive rats without affecting the blood pressure ${ }^{37}$, but naloxone had no effect on cocaine analgesia in our experiments. We cannot, however, rule out the possibility that cocaine produces other somatic or viscerai afferent activity that con- tributes to the activation of central analgesic mechanisms $^{26,38}$.

Our results provide strong evidence that both $D_{1}$ and $D_{2}$ dopamine receptor mechanisms are important in mediating cocaine analgesia because both the $D_{2}$ receptor antagonist, eticlopride, and the $D_{1}$ receptor antagonist, SCH 23390 , blocked cocaine analgesia in both the formalin and hot plate tests. In the formalin test, an anti-analgesic effect of both compounds might be seen if they each attenuated any anti-inflammatory effects of cocaine ${ }^{28}$. Because of the evidence for synergistic interactions of $D_{1}$ and $D_{2}$ receptor mechanisms ${ }^{4}$, it is not possible to conclude that these two receptor types are acting independently in mediating cocaine analgesia. A more complete analysis of agonist and antagonist dose-response functions will be required to determine receptor selectivity. Furthermore, a spinal or supraspinal analgesic action of other monoamine systems cannot be excluded on the basis of our studies.

The central neural mechanisms of cocaine analgesia remain to be determined. De Jong et al. ${ }^{7}$ and Woolf and Wiesenfeld-Hallin ${ }^{34}$ have presented evidence that systemically administered local anesthetics selectively block $\mathrm{C}$-fiber-evoked polysynaptic reflex activity in the spinal cord. The results of other experiments in our laboratory, however, suggest a supraspinal site for cocaine analgesia because analgesic doses of cocaine either potentiate or have no effect on a nociceptive spinal reflex ${ }^{23}$. The lack of evidence for spinal reflex inhibition and the lack of naloxone antagonism also argues against an opiate-mediated activation of supraspinal mechanisms that inhibit spinal nociceptive neurons by descending pathways $^{12,14}$. The dose of naloxone we used was sufficient to attenuate morphine analgesia in our tests and has been shown to blcck analgesia mediated by both $\mu$ - and $\delta$-opiate receptors ${ }^{11}$. Because cocaine is known to block the re-uptake deactivation of biogenic amines ${ }^{29.30}$, it might potentiate opiate analgesia, as shown by Misra et al. ${ }^{21}$, by enhancing the bulbospinal, biogenic amine-mediated inhibition of nocifensive spinal reflexes ${ }^{35}$. In contrast with our results, however, this potentiating effect of cocaine is blocked by naloxone ${ }^{21}$.

Evidence reviewed by Jensen ${ }^{19}$ shows that dopamine mechanisms can inhibit spinal nocifensive reflexes, but whether this inhibition is mediated by seg- 
mental spinal or by supraspinal descending dopamine pathways is not known. Dopamine-mediated inhibition of spinal reflexes may be independent of supraspinal dopamine neurons; we have shown that extensive chronic partial myelotomies markedly reduce spinal serotonin and norepinephrine, but not dopamine, concentrations in the cat $^{2}$. The effect of cocaine on supraspinally mediated behaviors and the dependence of cocaine analgesia on dopaminergic mechanisms suggests the participation of dopaminecontaining mesolimbic structures, which have been shown to be important for maintaining cocaine selfadministration and reinforcement in the rat ${ }^{33,39}$. The role of hypothalamic-related structures in dopaminemediated analgesia deserves further investigation in

1 Belczynski, C.R., Pertovaara, A., Morrow, T.J. and Casey, K.L., Cocaine: neurophysiological effects on bulboreticular projection neurons, Soc. Neurosci. Abstr., 13 (1987) 1588.

2 Casey, K.L., Morrow, T.J., Terry, L.C. and Craig, R., Differential effects of chronic partial myelotomies on monoamine levels in cat spinal cord, Brain Research, 408 (1987) 377-380.

3 Catelli, J.M., Sved, A.T. and Komisaruk, B.R., Vaginocervical probing elevates blood pressure and induces analgesia by separate mechanisms, Physiol. Behav., 41 (1987) 609-612.

4 Clark, D. and White, F.J., Review: D1 dopamine receptor - the search for a function: a critical evaluation of the D1/D2 dopamine receptor classification and its functional implications, Synapse, 1 (1987) 347-388.

5 Colville, K.I. and Chaplin, E., Sympathomimetics as analgesics: effects of methoxamine, methamphetamine, metaraminol and norepinephrine, Life Sci., 3 (1964) 315-322.

6 D'Amour, F.E. and Smith, D.L., A method of determining loss of pain sensation, J. Pharmacol. Exp. Ther., 72 (1941) 74-79.

7 De Jong, R.H., Robles, R. and Corbin, R.W.. Central actions of lidocaine - synaptic transmission, Anesthesiology, 30 (1969) 19-23.

8 DePaulis, T., Kumer, Y., Johansson, L., Ramsby, S., Hall, H., Sallemark, M., Angeby-Moller, K. and Ogren, S.-O., Potential neuroleptic agents. 4. Chemistry, behavioral pharmacology and inhibition of $\left[{ }^{3} \mathrm{H}\right]$-spiperone binding of 3,5-disubstituted $\mathrm{N}$-[(i-ethyl-Z-pyrrolidinyl)methyl]-6-methoxysalicylamides, J. Med. Chem., 29 (1986) 61-69.

9 Dubuisson, D. and Dennis, S.G., The formalin test: a quantitative study of the analgesic effects of morphine, meperidine, and brain stem stimulation in rats and cats, Pain, 4 (1977) 161-174.

10 Dworkin, B.R., Filewich, R.J., Miller, N.E. and Craigmyle, N., Baroreceptor activation reduces reactivity to noxious stimulation: implications for hypertension. Science, 205 (1979) 1299-1301.

11 Fang, P.G., Fields, H.L. and Lee, N.M., Action at the mu view of a recent report that cocaine causes the release of adrenocorticotropic hormone (ACTH) through the activation of corticotropin releasing factor $(\mathrm{CRF})^{28}$. There are additional, though conflicting, reports about the analgesic effects of CRF $^{15.31}$.

\section{ACKNOWLEDGEMENTS}

We gratefully acknowledge Patricia $M$. Morris and Scott M. Standish for their superior technical assistance with the data collection, statistical analysis and figure preparation required for this project. This work was supported by a grant from the Veterans Administration.

receptor is sufficient to explain the supraspinal analgesic effect of opiates, J. Pharmacol. Exp. Ther., 238 (1986) 1039-1044.

12 Fields, H.L. and Basbaum, A.I., Endogenous pain control mechanisms. In P.D. Wall and R. Melzack (Eds.), Textbook of Pain, Churchill and Livingstone, Edinburgh, 1984, pp. 141-152.

13 Fog, R., On stereotypy and catalepsy: studies on the effect of amphetamines and neuroleptics in rats, Acta Neurol. Scand., 48 (Suppl. 50) (1972) 7-25.

14 Gebhart, G.R., Opiate and opioid peptice effects on brain stem neurons: relevance to nociception and antinociceptive mechanisms, Pain, 12 (1982) 93-140.

15 Hargreaves, K.M., Mueller, G.P., Dubner, R., Goldstein, D. and Dionne, R.A., Corticntropin-releasing factor (CRF) produces analgesia in humans and rats, Brain $R_{e}$ search, 422 (1987) 154-157.

16 Harrison, P.W., The intravenous use of cocaine. Report of a case, Boston Med. Surg. J., 164 (1911) 151.

17 Hyttel, J., SCH 23390 - the first selective dopamine D-1 antagonist, Eur. J. Pharmacol., 91 (1983) 153-154.

18 Jaffe, J.H. and Martir, W.R., Opioid analgesics and antagonists. In A.G. Gilman, L.S. Goodman, T.S. Rall and T. Murao, (Eds.), The Pharmacological Basis of Therapeutics, Macmillan, New York, 1985, pp. 491-531.

19 Jensen, T.S., Antinociceptive systems: studies on spinal and supraspinal modulating mechanisms with particular reference to monoaminergic and opioid systems, Acta Neurol. Scand., Suppl. 108 (1986) 1-35.

20 Kast, L. and Meltzer, S.J., On the sensibility of abdominal organs and the influence of injections of cocaine upon it, Med. Rec., 70 (1906) 1017-1019.

21 Misra, A.L., Pontani, R.B. and Vadlamani, N.L., Stereospecific potentiation of opiate analgesia by cocaine: predominant role of noradrenaline, Pain, 28 (1987) 129-138.

22 O'Callaghan, J.P. and Holtzman, S.G., Quantification of the analgesic activity of narcotic antagonists by a modified hot-plate procedure, J. Pharmacol. Exp. Ther., 192 (1975) 497-505.

23 Pertovaara, A., Belczynski, C.R.. Morrow, T.J. and Cas- 
ey, K.L.. The effect of systemic cocaine on spinal nociceptive reflex activity in the rat, Brain Research, 438 (1988) 286-290.

24 Pitts, D.K., Udom, C.E. and Marwah, J., Cardiovascular effects of cocaine in anesthetized and conscious rats, Life Sci., 40 (1987) 1099-1111.

25 Randich, A. and Hartunian, C., Activation of the sinoaortic baroreceptor reflex arc induces analgesia: interactions between cardiovascular and endogenous pain inhibition systems, Physiol. Psychol., 11 (1983) 214-220.

26 Randich, A. and Maixner, W., The role of sinoaortic and cardiopulmonary baroreceptor reflex arcs in nociception and stress-induced analgesia, Ann. N.Y. Acad. Sci., 467 (1986) 385-401.

27 Ritter, C., Totalanasthesie durch injektion von cocain in die vene. Berliner Klin. Wochenschr., 46 (1909) 1701-1702.

28 Rivier, C. and Vale, W., Cocaine stimulates adrenocorticotropin (ACTH) secretion through a corticotropin-releasing factor (CRF)-mediated mechanism,Brain Research, 422 (1987) 403-406.

29 Ross, S.B. and Renyi, A.L., Inhibition of uptake of tritiated catecholamines by antidepressants and related drugs, Eur. J. Pharmacol., 2 (1967) 181-186.

30 Ross, S.B. and Renyi, A.L., Inhibition of uptake of 5-hydroxytryptamine in brain tissue, Eur. J. Pharmacol., 7 (1967) 270-277.

31 Sherman, J.E. and Kalin, N.H., ICV-CRH potently affects behavior without altering antinociceptive responding, Life Sci., 39 (1986) 433-441.

32 Whitby, L.G., Hertting, G. and Axelrod, J., Effect of co- caine on the disposition of noradrenaline labeled with tritium, Nature (Lond.), 187 (1960) 604-605.

33 Woods, J.H., Winger, G.D. and France, C.P., Reinforcing and discriminative stimulus effects of cocaine: analysis of pharmacological mechanisms. In A. Fisher, A. Raskin and E.H. Uhlenhuth (Eds.), Cocaine: Clinical and Biobehavioral Aspects, Oxford University Press, New York, 1987, pp. 21-65.

34 Woolf, C.J. and Wiesenfeld-Hallin, A., The systemic administration of local anesthetics produces a selective depression of C-afferent fiber evoked activity in the spinal cord, Pain, 23 (1985) 361-374.

35 Yaksh, T.L. and Hammond, D.L., Putative transmitters of descending systems - studies of local administration and liberation. In B. Sjölund and A. Björklund (Eds.), Brain Stem Control of Spinal Mechanisms, Elsevier, Amsterdam, 1982, pp. 473-492.

36 Yang, J.C., Clark, W.C., Dooley, J.C. and Mignogna, F.V., Effect of intranasal cocaine on experimental pain in man, Anesth. Analg., 61 (1982) 358-561.

37 Zamir, N., Simantov, R. and Segal, M., Pain sensitivity and opioid activity in genetically and experimentally hypertensive rats, Brain Research, 184 (1980) 299-310.

38 Zamir, $\mathbf{N}$. and Maixner, W., The relationship between cardiovascular and pain regulatory systems, Ann. N.Y. Acad. Sci., 467 (1986) 371-384.

39 Zito, K.A., Vickers, G. and Roberts, D.C.S., Disruption of cocaine and heroin self-administration following kainic acid lesions of the nucleus accumbens, Pharmacol. Biochem. Behav., 23 (1985) 1029-1036. 